\title{
REKONFIGURASI RELAI PROTEKSI SETELAH PENAMBAHAN PEMBANGKIT TERSEBAR PADA JARINGAN DISTRIBUSI
}

\author{
Nurul Mukhlisiah dan Adrianti* \\ Jurusan Teknik Elektro, Fakultas Teknik, Universitas Andalas \\ *Corresponding author, e-mail : adrianti@ft.unand.ac.id
}

\begin{abstract}
Abstrak - Pemasangan Pembangkit Tersebar (PT) di jaringan distribusi dapat mengubah arah aliran arus saat kondisi normal dan kondisi gangguan. Hal ini dapat menyebabkan relai-relai proteksi yang sudah ada sebelum pemasangan PT tidak bekerja sebagaimana seharusnya. Relai dapat mengalami maloperasi ataupun tidak berhasil mendeteksi adanya gangguan di daerah proteksinya. Untuk itu, perlu dilakukan pengkajian ulang terhadap kerja dan koordinasi relai-relai setelah penambahan DG. Pada tulisan ini, dilakukan upaya rekonfigurasi dan resetting relai-relai proteksi setelah penambahan PT di bagian yang sensitif dari jaringan distribusi, yaitu bagian paling hilir. Perbaikan dilakukan dengan menambahkan relai arus lebih berarah untuk mengantisipasi sumber arus gangguan dari grid dan PT yang berbeda arah, serta setting ulang relai-relai akibat perubahan yang disebabkan oleh pemasangan PT. Selanjutnya, dilakukan pengujian koordinasi relai yang telah direkonfigurasi dan diresetting tersebut menggunakan software ETAP. Untuk mengantisipasi kondisi PT yang dapat berubah dilakukan variasi kapasitas PT yaitu kapasitas penuh, setengah kapasitas dan kondisi PT terlepas dari jaringan. Pengujian urutan kerja relai ini dilakukan pada berbagai titik gangguan dan untuk setiap titik gangguan disimulasikan 3 jenis gangguan yaitu gangguan tiga fasa, antar fasa dan satu fasa ke tanah. Dari pengujian tersebut didapatkan bahwa rekonfigurasi dan resetting yang sudah dilakukan berhasil memberikan koordinasi relai yang benar untuk ketiga macam kapasitas PT tersebut.
\end{abstract}

\section{Kata Kunci :, Pembangkit Tersebar, Relai arus lebih berarah, Koordinasi proteksi.}

\begin{abstract}
Installation of distributed generation (DG) on a distribution network can change the direction of electrical current during normal and faulted condition. This change can cause failures to operate of the existing relay protection. The failures are including unwanted operation and protection blinding. Therefore, evaluation of the existing protection after DG installation is needed. This paper proposes a method for reconfiguration and resetting of the relays after installation of a DG on the sensitive part of a distribution network i.e. the very downstream of the distribution network. The reconfiguration suggests the application of directional overcurrent relay in order to distinguish the sources of fault current: from the grid and from the DG. The reconfiguration and the resetting results then are simulated in ETAP software. The simulation is carried out for several variation i.e. DG capacity, type of fault and fault position on the network. From the simulation can be concluded that the reconfiguration and resetting of the protection relays after installation of the DG have provided a correct operation of protection coordination as intended to.
\end{abstract}

Keywords: Distributed Generation (DG), Directional Overcurrent Relay, Protective Coordination.

Copyright $\subset 2017$ JNTE. All rights reserved

\section{PENDAHULUAN}

Strategi yang sangat populer untuk memenuhi kebutuhan energi listrik yang terus meningkat adalah dengan menggunakan Pembangkit Tersebar (PT). Pembangkit Tersebar didefinisikan sebagai pembangkit tenaga listrik berskala kecil yang ditempatkan pada jaringan distribusi atau pada sisi jaringan pelanggan. PT memberikan berbagai kelebihan dibandingkan pembangkitan konvensional seperti lebih ramah lingkungan, mengurangi rugi-rugi transmisi dan sekaligus mengurangi kebutuhan investasi peningkatan kapasitas saluran transmisi. Akan tetapi PT juga berpotensi menimbulkan permasalahan baru yang salah satunya adalah terjadinya kesalahan operasi dari relai proteksi yang sudah ada sebelum pemasangan PT $[1,2]$.

Pada penelitian [1], didapatkan bahwa penempatan PT pada jaringan distribusi dapat menyebabkan kesalahan operasi dan koordinasi relai proteksi yang sudah ada, baik pada saat kondisi gangguan maupun saat kondisi normal. 
Maloperasi relai arus lebih saat tidak ada gangguan terjadi karena adanya peningkatan arus nominal akibat suplai dari PT yang besarnya melebihi setting relai. Sehingga pada [1] dilakukan investigasi kapasitas maksimum PT yang dapat dipasang, agar tidak menyebabkan terjadinya kesalahan operasi relai proteksi. Hasil penelitian tersebut menyimpulkan bahwa semakin ke hilir dari grid, maka semakin kecil kapasitas PT yang dapat dipasang.

Untuk dapat memanfaatkan secara maksimal potensi PT di berbagai lokasi di jaringan distribusi, perlu dicari solusi bagi permasalahan sistem proteksi tersebut. Relai proteksi perlu direkonfigurasi dan disetting ulang agar dapat mengantisipasi keadaan gangguan dan keadaan tanpa gangguan setelah penempatan PT.

Pada penelitian ini, dilakukan rekonfigurasi dan setting ulang sistem proteksi pada jaringan distribusi yang dibahas pada [1] setelah penempatan sebuah PT berkapasitas $2 \mathrm{MW}$ di bagian hilir saluran. Tipe PT yang dipasang adalah PT yang menggunakan generator sinkron. Penggunaan generator sinkron dilakukan karena besar dan lama arus gangguan yang dihasilkan oleh generator sinkron lebih signifikan dari pada generator induksi atau inverter [2-4].

\section{PENGARUH PEMBANGKIT TERSEBAR TERHADAP ARUS SAAT KONDISI NORMAL DAN GANGGUAN DAN ANTISIPASI SISTEM PROTEKSI}

Aliran arus kondisi normal dapat berubah jika output PT melebihi permintaan lokal. Untuk kondisi ini, PT mengekspor listrik ke sisi hulu jaringan atau bahkan ke grid. Jika ekspor daya cukup besar, maka arus yang terbaca oleh relai dapat lebih besar dari pada setting relai, maka sistem proteksi akan mengalami maloperasi.

Kondisi ini dapat diatasi dengan menaikkan setting arus relai atau mengganti jenis relai menjadi relai arus lebih berarah. Menaikkan setting arus relai harus dilakukan dengan hatihati karena dapat memungkinan relai menjadi gagal beroperasi (blinding) saat terjadinya gangguan karena arus gangguan yang terjadi lebih kecil dari setting baru tersebut.

Untuk mencegah kondisi blinding ini, penggunaan relai arus lebih berarah lebih dianjurkan. Selain itu penambahan relai berarah pada kedua ujung saluran dapat memisahkan proteksi berdasarkan sumber arus (dari grid dan dari PT), sehingga setting relai lebih mudah dilakukan.

Saat terjadi gangguan di jaringan, PT akan menyuplai arus gangguan ke titik gangguan. PT menjadi sumber arus gangguan baru selain suplai dari grid. Jika terjadi gangguan pada saluran lain yang berdekatan dengan lokasi PT seperti ditunjukkan pada Gambar 1, maka relai R2 harus beroperasi. Namun, karena PT menyuplai arus gangguan ke bagian yang terganggu, relai R1 membaca arus yang mengalir melebihi arus settingnya, sehingga $R 1$ juga akan beroperasi. Untuk mengatasi hal tersebut, R1 diganti dengan relai arus lebih berarah ke hilir (forward) sehingga tidak akan trip saat arus dari PT mengalir ke titik gangguan.

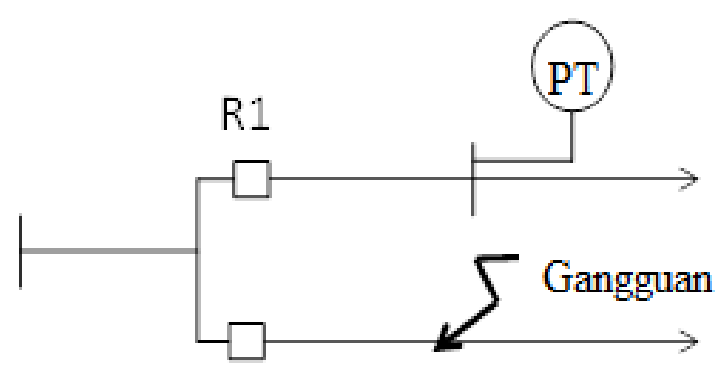

R2

Gambar 1. Gangguan yang terjadi berdekatan dengan Pembangkit Tersebar [4]

Sebelum adanya PT, arus gangguan hanya berasal dari grid, sehingga relai proteksi hanya dibutuhkan di bagian pangkal saluran-saluran, seperti ditunjukkan Gambar 2. Jika PT ditempatkan dibagian hilir dari jaringan, maka saat terjadi gangguan di jaringan, relai proteksi harus mampu memutus suplai arus gangguan baik dari grid maupun dari PT. Kedua suplai ini dapat mempunyai arah yang berlawanan, sehingga diperlukan relai proteksi pada kedua ujung saluran atau pada kedua sisi peralatan di jaringan distribusi, seperti ditunjukkan pada Gambar 3. Sebelum PT dipasang di jaringan, relai R1 pada Gambar 2 adalah relai arus lebih biasa, sedangkan setelah penambahan PT, R1 memerlukan kemampuan membedakan arah arus gangguan, yaitu hanya untuk arus gangguan yang disuplai dari grid (arah ke hilir/forward). Untuk arus gangguan yang berasal dari PT, dibutuhkan tambahan relai arus lebih berarah ke hulu/reverse yaitu R2 yang ditunjukkan oleh Gambar 3. 


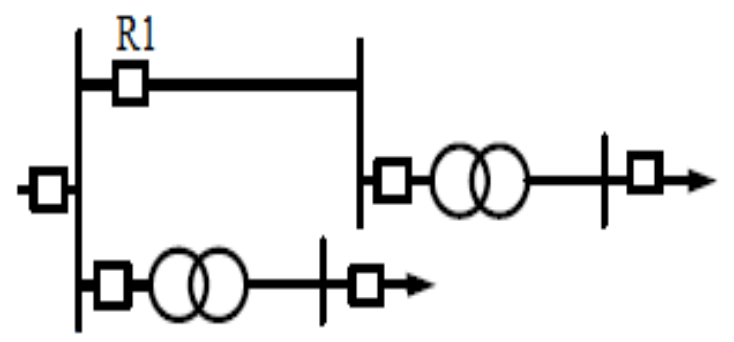

Gambar 2. Relai proteksi pada jaringan distribusi sebelum penempatan PT.

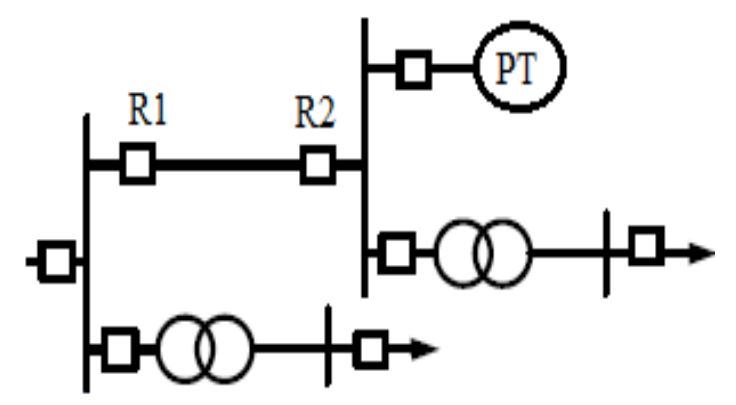

Gambar 3. Relai proteksi pada jaringan distribusi setelah penambahan PT.

\section{METODE PENELITIAN}

Langkah-langkah rekonfigurasi dan setting ulang relai proteksi setelah pemasangan PT adalah sebagai berikut:

Setelah data sistem diperoleh, dilakukan pemodelan sistem tenaga listrik berupa single line diagram pada software ETAP 12.6

Selanjutnya dilakukan simulasi aliran daya untuk mengetahui arus nominal. Simulasi gangguan hubung singkat pada berbagai titik gangguan untuk mengetahui arus gangguan hubung singkat yang terlihat oleh masingmasing relai. Kedua nilai ini diperlukan untuk perhitungan setting relai

Berbagai titik gangguan pada jaringan diamati untuk melihat arah arus gangguan yang datang dari grid dan dari PT. Jika kedua sumber arus gangguan ini datang dari arah yang sama, maka tidak diperlukan penggantian relai menjadi relai berarah. Sebaliknya jika kedua arus gangguan tersebut datang dari arah yang berlawanan, maka akan dibutuhkan dua relai dengan setting arah yang berlawanan pada kedua ujung saluran atau komponen sistem distribusi.

Selanjutnya dilakukan perhitungan setting relai arus lebih dan relai arus lebih berarah.
Setting dan koordinasi relai proteksi dihitung menggunakan rumus sebagai berikut $[5,6]$ :

$$
\begin{aligned}
& I_{\text {set }}=1.1 \times \text { arus nominal }\left(I_{n}\right) \\
& I_{\text {pick up }}=I_{\text {set }} \times \frac{\text { sekunder } C T}{\text { primer } C T} \\
& P S M=\frac{I_{\text {fault }}}{I_{\text {pickup }}} \\
& t_{\text {op }}=T M S \times\left[\frac{0,14}{(P S M)^{0,02}-1}\right]
\end{aligned}
$$

Dimana $I_{\text {set }}$ adalah setting arus relai dalam besaran sisi primer $\mathrm{CT}$, sedangkan $I_{\text {pick up }}$ adalah nilai $I_{\text {set }}$ setelah ditranformasi oleh CT. $t_{o p}$ adalah waktu operasi relai. Perhitungan setting waktu untuk relai berarah dilakukan dengan memperhatikan relai mana yang menjadi relai utama dan mana yang menjadi relai back up sesuai arah relai dan arah arus gangguan.

Kemudian, untuk mengecek kebenaran setting yang akan diaplikasikan ke masingmasing relai, dilakukan simulasi operasi relai dengan software ETAP. Dari simulasi untuk suatu titik gangguan, akan dapat diketahui urutan trip dari relai-relai yang ada. Sehingga dapat dicek apakah koordinasi relai sudah sesuai dengan yang diinginkan. Jika koordinasi relai belum sesuai, dilakukan perbaikan setting relai. Jika sudah sesuai, lakukan pengecekan untuk titik-titik gangguan lainnya di dalam jaringan.

Karena dalam operasinya PT dapat terkoneksi atau terputus dari sistem, maka perlu diketahui apakah setting relai yang telah diperoleh masih dapat bekerja dengan baik untuk berbagai kondisi PT. Untuk itu simulasi dilakukan untuk 3 macam kapasitas PT yaitu kapasitas maksimum, setengah kapasitas dan PT dilepas dari sistem.

\section{HASIL DAN PEMBAHASAN}

Pada penelitian ini dilakukan rekonfigurasi relai proteksi pada sistem distribusi yang dibahas pada [1]. Single line diagram sebelum penambahan PT disajikan pada Gambar 4. Sebuah PT dengan kapasitas 2 MW dipasang pada Bus 6 (Gambar 5). Akibat pemasangan PT tersebut, sistem proteksi mengalami maloperasi dan kesalahan koordinasi relai. Sehingga diperlukan rekonfigurasi dan setting ulang relairelai proteksi. 


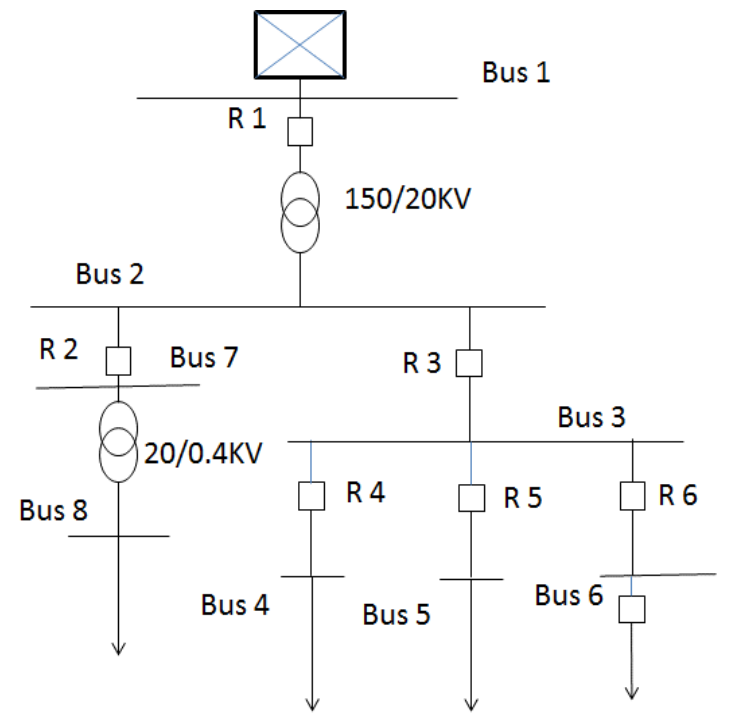

Gambar 4. Jaringan distribusi sebelum penambahan PT [1]

Jika terjadi gangguan pada saluran dari bus 3 ke bus 6, arus gangguan akan mengalir dari dua arah yang berlawanan yaitu dari grid (hulu) dan dari PT (hilir) akibatnya dibutuhkan relai arus lebih pada kedua ujung saluran tersebut (R6 dan R7) seperti ditunjukkan pada Gambar 5.

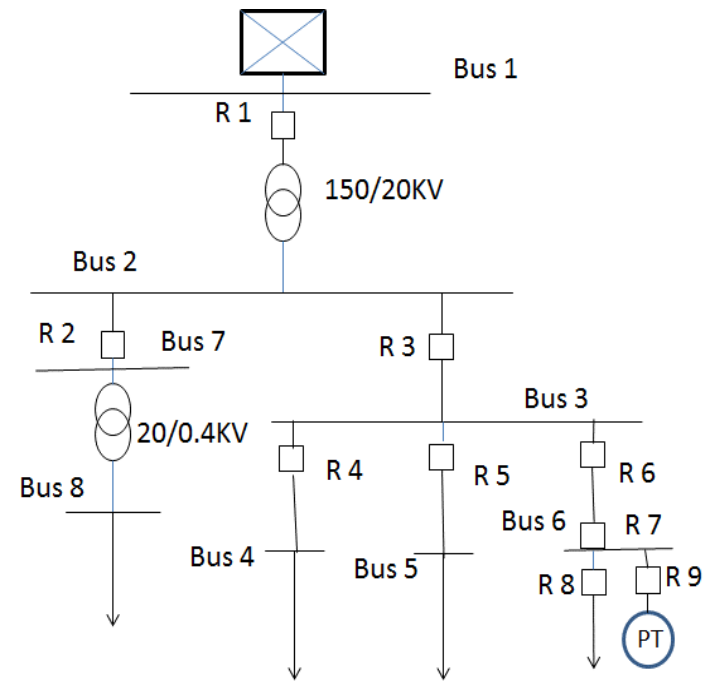

Gambar 5. Rekonfigurasi relai setelah pemasangan PT pada bus 6

R6 diganti menjadi relai arus lebih berarah forward dan R7 merupakan penambahan relai arus lebih berarah yang diset melihat arus ke arah hulu (reverse). Penempatan relai arus lebih berarah pada kedua ujung saluran selain untuk memutuskan arus gangguan dari grid dan dari PT jika terjadi gangguan di saluran tersebut, juga untuk mencegah maloperasi relai saat terjadi gangguan di bagian lain di dalam jaringan.

Penempatan PT pada bus 6 mengakibatkan diperlukannya pemasangan relai arus lebih $\mathrm{R} 9$ pada terminal PT dan R8 pada jaringan di hilir Bus 6. R9 diset untuk berkoordinasi dengan R7, sedangkan R6 berkoordinasi dengan R8. Jika terjadi gangguan pada saluran antara Bus 3 dan Bus 6 maka arus dari grid akan diputus oleh R6 yang jika gagal akan dibackup oleh R3 kemudian $\mathrm{R} 1$. Sedangkan arus dari PT akan diputus oleh R7 yang dibackup oleh R9. Untuk gangguan yang terjadi pada Bus 6, maka arus dari grid akan diputus oleh R6 dengan backup R3 kemudian R1, sedangkan arus dari PT akan diputus oleh R9. Selain itu, R7 juga berfungsi sebagai relai backup untuk memutus arus dari PT saat terjadi gangguan dibagian lain dari jaringan

Berdasarkan hasil simulasi aliran daya, simulasi gangguan dan urutan koordinasi masing-masing relai dilakukan perhitungan setting relai-relai di jaringan. Hasil perhitungan setting masing-masing relai ditunjukkan pada Tabel 1 .

Tabel 1. Setting masing-masing relai setelah penambahan pembangkit tersebar

\begin{tabular}{|c|c|c|c|}
\hline Nama Relai & arah & Iset A & TMS \\
\hline R1 & - & 9,9 & 0,765 \\
\hline R2 & - & 2 & 0,362 \\
\hline R3 & - & 72,16 & 0,458 \\
\hline R4 & - & 30,91 & 0,262 \\
\hline R5 & - & 28,49 & 0,248 \\
\hline R6 & forward & 13,31 & 0,264 \\
\hline R7 & reverse & 5,388 & 0,485 \\
\hline R8 & - & 14,9 & 0,05 \\
\hline R9 & - & 18,04 & 0,46 \\
\hline
\end{tabular}

Untuk pengujian koordinasi relai, jaringan distribusi diberi gangguan di berbagai lokasi guna melihat urutan relai yang bekerja. Pengujian koordinasi juga dilakukan dengan variasi kapasitas PT (2 MW, 1 MW dan PT terlepas).

Rekapitulasi hasil pengujian koordinasi relai pada variasi kapasitas PT: $2 \mathrm{MW}, 1 \mathrm{MW}$ dan 0 $\mathrm{W}$, ditunjukan pada Tabel 2 dan Table 3. Pada 
pengujian tersebut, gangguan yang disimulasikan meliputi gangguan 3 fasa, antar fasa dan satu fasa ke tanah. Tidak terdapat perbedaan urutan trip relai untuk ke tiga macam jenis gangguan tersebut.

Urutan trip relai yang diperoleh untuk kapasitas PT 2 MW sama dengan urutan untuk kapasitas PT 1 MW seperti yang ditunjukkan pada Tabel 2. Hal ini menunjukkan bahwa konfigurasi dan setting yang dibuat dapat digunakan untuk kondisi dimana semua unit PT beroperasi maupun saat sebagian unit PT dalam keadaan tidak beroperasi.

Tabel 2. Rekapitulasi pengujian koordinasi relai dengan kapasitas PT 2 MW dan 1 MW

\begin{tabular}{|c|c|c|c|c|}
\hline $\begin{array}{c}\text { Lokasi } \\
\text { gangguan }\end{array}$ & $\begin{array}{l}\text { Proteksi } \\
\text { Utama }\end{array}$ & \begin{tabular}{|c|} 
Proteksi \\
Cadangan \\
1 \\
\end{tabular} & $\begin{array}{c}\text { Proteksi } \\
\text { Cadangan } \\
2 \\
\end{array}$ & Ket \\
\hline \multirow{2}{*}{ Di hulu R8 } & R8 & $\longrightarrow$ R6 & $\rightarrow \mathrm{R} 3$ & Sesuai \\
\hline & & $\searrow \mathrm{Rg}$ & & Sesuai \\
\hline \multirow[t]{2}{*}{ Bus 6} & R6 & $\rightarrow \mathrm{R} 3$ & $\rightarrow \mathrm{R} 1$ & Sesuai \\
\hline & R9 & & & Sesuai \\
\hline \multirow[t]{2}{*}{$\begin{array}{c}\text { Saluran dari Bus } \\
3 \text { ke Bus } 6\end{array}$} & R6 & $\rightarrow \mathrm{R} 3$ & $\rightarrow \mathrm{R} 1$ & Sesuai \\
\hline & R7 & $\rightarrow \mathrm{R} 9$ & & Sesuai \\
\hline \multirow[t]{2}{*}{ Bus 5} & R5 & $\rightarrow \mathrm{R} 3$ & $\rightarrow \mathrm{R} 1$ & Sesuai \\
\hline & & $\checkmark$ R7 & $\rightarrow \mathrm{Rg}$ & Sesuai \\
\hline \multirow[t]{2}{*}{ Bus 4} & R4 & $\rightarrow \mathrm{R} 3$ & $\rightarrow \mathrm{R} 1$ & Sesuai \\
\hline & & $\begin{array}{l}\text { R7 } \\
\end{array}$ & R9 & Sesuai \\
\hline \multirow[t]{2}{*}{ Bus 3} & R3 & $\rightarrow \mathrm{R} 1$ & & Sesuai \\
\hline & R7 & $\rightarrow \mathrm{R} 9$ & & Sesuai \\
\hline \multirow[t]{2}{*}{ Bus 2} & R1 & & & Sesuai \\
\hline & R7 & $\rightarrow \mathrm{R} 9$ & & $\mathrm{OK}$ \\
\hline \multirow[t]{2}{*}{$\begin{array}{c}\text { Saluran Bus } 2 \text { ke } \\
\text { Bus } 8 \\
\end{array}$} & $\mathrm{R} 2$ & R1 & & Sesuai \\
\hline & & $\searrow$ R7 & $\rightarrow \mathrm{Rg}$ & Sesuai \\
\hline \multirow[t]{2}{*}{$\begin{array}{c}\text { SaluranBus } 2 \text { ke } \\
\text { Bus } 3\end{array}$} & R3 & $\longrightarrow \mathrm{R} 1$ & & Sesuai \\
\hline & R7 & $\rightarrow \mathrm{Rg}$ & & Sesuai \\
\hline
\end{tabular}

Konfigurasi dan setting yang sama juga berhasil bekerja sesuai dengan urutan koordinasi yang diharapkan untuk kondisi PT terlepas dari sistem, seperti ditunjukkan pada Tabel 3. Dari Tabel 3 dapat dilihat bahwa relai dengan arah reverse (R7) dan relai pada terminal PT (R9) tidak pernah trip, karena tidak ada arus gangguan yang disuplai dari PT.
Tabel 3. Rekapitulasi pengujian koordinasi relai penambahan PT $0 \mathrm{~kW}$

\begin{tabular}{|c|c|c|c|c|}
\hline $\begin{array}{c}\text { Lokasi } \\
\text { gangguan }\end{array}$ & $\begin{array}{c}\text { Proteksi } \\
\text { Utama }\end{array}$ & \begin{tabular}{|c|} 
Proteksi \\
Cadangan \\
1
\end{tabular} & \begin{tabular}{|c|} 
Proteksi \\
Cadangan \\
2
\end{tabular} & Ket \\
\hline Di hulu R8 & R8 & $\longrightarrow \mathrm{R} 6$ & $\rightarrow \mathrm{R} 3$ & Sesuai \\
\hline Bus 6 & R6 & $\rightarrow \mathrm{R} 3$ & $\rightarrow \mathrm{R} 1$ & Sesuai \\
\hline $\begin{array}{c}\text { Saluran dari Bus } \\
3 \text { ke Bus } 6\end{array}$ & R6 & $\rightarrow \mathrm{R} 3$ & $\rightarrow \mathrm{R} 1$ & Sesuai \\
\hline Bus 5 & R5 & $\rightarrow \mathrm{R} 3$ & $\rightarrow \mathrm{R} 1$ & Sesuai \\
\hline Bus 4 & R4 & $\rightarrow \mathrm{R} 3$ & $\rightarrow \mathrm{R} 1$ & Sesuai \\
\hline Bus 3 & R3 & $\rightarrow \mathrm{R} 1$ & & Sesuai \\
\hline Bus 2 & R1 & & & Sesuai \\
\hline $\begin{array}{c}\text { Antara Bus } 2 \text { ke } \\
\text { Bus } 8 \\
\end{array}$ & R2 & $\rightarrow$ & & Sesuai \\
\hline $\begin{array}{c}\text { SaluranBus } 2 \text { ke } \\
\text { Bus } 3\end{array}$ & R3 & $\longrightarrow \mathrm{R} 1$ & & Sesuai \\
\hline
\end{tabular}

\section{KESIMPULAN}

Dari hasil perhitungan, simulasi dan analisa yang dilakukan, dapat diambil kesimpulan bahwa rekonfigurasi sistem proteksi dengan penambahan 2 unit relai arus lebih berarah dan 2 unit relai arus lebih serta perubahan setting relai pada jaringan distribusi dengan pembangkit tersebar, telah berhasil beroperasi saat terjadi gangguan didalam zona proteksinya dan mencegah maloperasi saat terjadi gangguan di luar daerah proteksinya.

Koordinasi relai saat penambahan PT dengan variasi kapasitas $2 \mathrm{MW}, 1 \mathrm{MW}$ dan kondisi PT terputus dari jaringan, sudah bekerja dengan baik. Hal ini ditandai dengan kesesuaian antara hasil simulasi koordinasi relai yang dilakukan dengan koordinasi yang diharapkan.

Pada penelitian selanjutnya, disarankan agar dapat membahas skema proteksi pada kondisi grid terputus dari sistem dan PT bekerja secara islanding di jaringan distribusi.

\section{DAFTAR PUSTAKA}

[1] A. Adrianti and R. Prasetya, "Maximum Capacities of Distributed Generation in order to Avoid Failures of the Overcurrent Relay Coordination on a Distribution 
Networks," Jurnal Nasional Teknik Elektro, vol. 5, (2016).

[2] M. H. Bollen and F. Hassan, Integration of distributed generation in the power system vol. 80: John Wiley \& Sons, (2011).

[3] S. K. Salman and I. M. Rida, "Investigating the Impact of Embedded Generation on Relay Settings of Utilities' Electrical Feeders," IEEE Transaction on Power Delivery, vol. 16, pp. 246-251, (2001).

[4] T. N. Boutsika and S. A. Papathanassiou, "Short-circuit calculations in networks with distributed generation," Electric Power Systems Research, vol. 78, pp. 1181-1191, (2008).

[5] Alstom-Grid. Network Protection \& Automation Guide. (2011) Available: http://www.alstom.com/grid/productsand-services/Substation-automation-
system/protection-relays/NetworkProtection-Automation-Guide-NEW2011-Edition/

[6] Y. G. Paithankar and S. R. Bhide, Fundamentals of power system protection. New Delhi: PHI Learning Private Limited, (2010).

\section{Biodata Penulis}

Adrianti, Saat ini bertugas sebagai dosen di Jurusan Teknik Elektro, Universitas Andalas, Padang, Indonesia. Dia menyelesaikan studinya di Universitas Sriwijaya dan gelar magister di Institut Teknologi Bandung. Dia menyelesaikan studi $\mathrm{PhD}$ di University of Strathclyde, Glasgow, Inggris pada tahun 2015. 